\title{
Respiratory Morbidities and Lung Function Abnormalities in Survivors of Bhopal Gas Disaster: A Cross-Sectional Study
}

Sajal De ( $\nabla$ sajalde@yahoo.com )

ALL India Institute of medical sciences https://orcid.org/0000-0002-8349-125X

Nalok Banerjee

National Institute for Research in Environmental Health

Yogesh Sabde

National Institute for Research in Environmental Health

\section{Research Article}

Keywords: Bhopal Gas disaster, respiratory morbidity, forced oscillation technique, spirometry, small airway dysfunction

Posted Date: June 25th, 2021

DOI: https://doi.org/10.21203/rs.3.rs-656436/v1

License: @) (7) This work is licensed under a Creative Commons Attribution 4.0 International License. Read Full License

Version of Record: A version of this preprint was published at Respiratory Investigation on October 1st, 2021. See the published version at https://doi.org/10.1016/j.resinv.2021.09.008. 


\section{Abstract \\ Background}

Respiratory morbidities remained major morbidities among the survivors of the Bhopal gas disaster. We hypothesized that underlying lung function abnormalities, especially small airway dysfunctions (SAD), were responsible for persistent respiratory morbidity.

\section{Material and methods}

We conducted a cross-sectional study between 2018 and 2020 in the severely exposed cohort of the Bhopal gas disaster. A standardized questionnaire was used to collect respiratory symptoms. The forced oscillation technique (FOT) and spirometry were used for assessing lung functions. Univariate and multivariate logistic regression analyses were used to examine the association.

\section{Results}

Total 916 individuals (men: 442) participated. The mean age was $55.2 \pm 12.3$ years. Breathlessness was a predominant respiratory complaint (71.7\%), followed by cough (15.1\%). Five hundred fifty-eight individuals participated in lung function assessment. The R5 > ULN (upper limit of normal), $R_{5-19}>U L N$, and X5 < LLN (lower limit of normal) were observed in 29.3\%, 23.3\%, and 21.2\% participants, respectively. Normal, obstructive, and restrictive spirometry was observed in $46.2 \%, 26.1 \%$, and $27.7 \%$ of participants, respectively. Abnormalities in FOT parameters were observed in $25.3 \%$ of individuals with normal spirometry. Individuals with obstructive spirometry had the highest risk of abnormal FOT parameters (adj OR:3.93, 95\% Cl: 2.24-6.89). Breathlessness showed a significant association with abnormal R5 (adj OR: 1.81; 95\% Cl: 1.13-2.91) and obstructive spirometry (adj OR: 2.26; 95\% Cl: 1.29-3.95).

\section{Conclusion}

Assessment of small airway functions, in addition to spirometry, will help to identify complex lung function abnormalities in the population exposed to toxic inhalation.

\section{Key Messages}

What is the key question? Respiratory morbidity remained significant morbidity in survivors of the Bhopal gas disaster. The studies conducted during the initial period demonstrated diverse abnormalities in spirometry.

\section{What is the bottom line?}

This study was the first to investigate small airway dysfunction in the gas-exposed survivors. We observed a high prevalence of abnormalities in both spirometry and forced oscillation techniques parameters. The small airway dysfunction was independent of the abnormality in spirometry. Respiratory morbidity showed a significant association with abnormalities in lung function.

\section{Why read on?}

This study emphasized that spirometry is insufficient to detect complex lung function abnormalities in participants exposed to toxic gases. The small airway function must be assessed in such a situation.

\section{Introduction}

Bhopal gas disaster is one of the worst chemical disasters in the world. On 3rd December 1984, toxic gases were leaked at Bhopal (capital of state Madhya Pradesh, India) from a nearby pesticide plant. Several thousand individuals were exposed to these toxic gases, and many died. After the disaster, the Municipal Corporation of Bhopal categorized the Bhopal city (wards) into gas-affected and non-affected areas based on the severity of symptoms in the residents of those areas. ${ }^{1}$ The gas-affected areas were further stratified into mild, moderate, and severely affected areas based on the mortality rate between 3rd and 6th December 1984.

In 1985, the Indian Council of Medical Research (ICMR) started the long-term population-based epidemiological study to assess the long-term health effects of toxic gas exposure. Cohorts for that study were assembled by randomly recruiting individuals from both gas-affected and non-affected areas. The stratification of mild, moderate, and severely exposed cohorts was based on the recruited subjects' residential addresses. Formation of cohorts and morbidity profile of these cohorts over the last thirty years had been published. ${ }^{1-3}$ Respiratory morbidities continued to be one of the commonest morbidities in the exposed cohorts. We hypothesized that lung function abnormalities, especially small airway dysfunction (SAD), are responsible for persistent respiratory symptoms.

The aim of our study was (i) to characterize the respiratory symptoms, (ii) to assess lung function by forced oscillation technique (FOT) and spirometry, and (iii) to assess the relationships of respiratory symptoms with lung function abnormalities in survivors of the Bhopal gas disaster.

\section{Methods}




\section{Study population}

This community-based cross-sectional study was conducted from February 2018 to February 2020. The Institutional Ethics Committee of the National Institute for Research in Environmental Health approved the study protocol (NIREH/BPL/1EC-prj.19/2017-18/1458). The initial plan was to recruit from all cohorts, but permission to recruit only from the severely exposed cohort was granted. The cohort population of the ICMR study was variable on each survey since inception due to the high attrition rates. ${ }^{1-3}$ The number of individuals of the severe cohort available before the initiation of this study was 4170 . Therefore, we decided to recruit 4000 severely exposed. The exclusion criteria were those who declined to take part and unavailable on two attempts. An earlier study showed that individuals with age $<20$ years at the time of the disaster had lesser respiratory morbidity than those with age $\geq 20$ years. ${ }^{3}$ Therefore, we stratified our study participants into two age groups: age $\leq 55$ years (i.e., age was $\leq 20$ years at the time of the disaster) and age more than 55 years (i.e., age $>20$ years at the time of the disaster) to verify the previous observation.

\section{Characterization of chronic respiratory symptoms}

We developed a questionnaire based on the INSEARCH (Indian Study on Epidemiology of Asthma, respiratory symptoms and Chronic Bronchitis) questionnaire to characterize respiratory symptoms and smoking habits. ${ }^{4}$ The death of family members (living with them) within one year from the disaster, whether admitted to a hospital within one week after the exposure, the distance of residence from the pesticide plant at the time of exposure, and treatment received for other co-morbidities (e.g., diabetes, hypertension, coronary artery disease, chronic kidney diseases, etc.) were also collected. A trained technician administered the questionnaire during home visits. The principal investigator re-examined the responses at the time of lung function testing. The complaint of breathlessness was defined as an affirmative response to at least one of the questions on breathlessness in different situations, i.e., a feeling of morning breathlessness, breathlessness on exertion, breathlessness without exertion, and breathlessness at night. The cough complaint was defined as an affirmative response to either having cough in the morning or at night. The diagnosis of chronic bronchitis was based on the cough with expectoration for $\geqslant 3$ months with an affirmative response to one of the two questions, i.e., usually first cough in the morning and bring out phlegm from the chest first time in the morning. Those who consented to lung function testing were bought to our respiratory clinic.

\section{Forced Oscillatory Technique (FOT)}

The respiratory system resistance (Rrs) and reactance (Xrs) were measured by the Resmon Pro Full device (Restech Srl, Milan, Italy) at 5, 11, and 19 Hz sinusoidal signals. The equipment was calibrated daily before the procedure with reference impedance. The age in completed years, gender, standing height to the nearest centimeter without shoes, and weight rounded off to the nearest kilogram were recorded. FOT was performed in an upright sitting position, putting the nose clip, supporting the cheeks, and according to the European Respiratory Society's recommendation. ${ }^{5}$ Each individual performed at least three FOT, and each test was continued until 15 accepted breaths were recorded. The mean of three acceptable tests was retained for the analysis. The FOT parameters included in this analysis were whole-breath respiratory system resistance at $5 \mathrm{~Hz}$ (R5), whole-breath respiratory system reactance at $5 \mathrm{~Hz}$ (X5), and frequencydependence of resistance calculated as the difference of whole-breath resistance at 5 and $19 \mathrm{~Hz}\left(\mathrm{R}_{5-19}\right)$. We published the predicted values with the upper limit of normal (ULN) and lower limit of normal (LLN) of each FOT parameter for healthy Indian adults. ${ }^{6}$ Until now, the standards to describe the abnormality of FOT parameters have not been developed. ${ }^{7}$ Therefore, we considered R5 and $\mathrm{R}_{5-19}$ were abnormal if the recorded values were higher than the ULN; and X5 was abnormal if the recorded values were lower than the LLN. An abnormal FOT was defined as abnormal R5 or $\mathrm{R}_{5-19}$, or X5, or all three parameters were abnormal.

\section{Spirometry:}

After FOT, spirometry was performed according to the ATS-ERS recommendation using PowerCube Diffusion+ (GANSHORN Medizin Electronic, Germany). ${ }^{8}$ Spirometry was performed in a sitting position and wearing a nose clip. Each participant performed at least three acceptable maximal forced expiratory maneuvers. The highest value of forced vital capacity (FVC) and forced expiratory volume in one second (FEV 1 ) were recorded. The North Indian regression equations were used to estimate the predicted values of spirometry parameters, and the lower limit of normal (LLN) was set at the $5^{\text {th }}$ percentile. ${ }^{9}$ If both $\mathrm{FEV}_{1} / \mathrm{FVC} \geq 0.70$ and $\mathrm{FVC} \geq \mathrm{LLN}$, spirometry was categorized as normal spirometry. If $\mathrm{FEV}_{1} / \mathrm{FVC}<0.70$, spirometry was categorized as an obstructive pattern according to the GOLD (Global Initiative for Chronic Obstructive Lung Disease) guideline. ${ }^{10}$ If FEV $1 / F V C \geq 0.70$ and FVC $<$ LLN, spirometry was categorized as a restrictive pattern. The severities of obstruction and restriction were based on $\mathrm{FEV}_{1} \%$ of predicted according to the ATS-ERS recommendation, i.e., mild ( $\geq 70$ ); moderate ( $\geq 60$ to $<70$ ); moderately severe $(\geq 50$ to $<60)$; severe $\left(\geq 35\right.$ to $<50$ ); and very severe $(<35){ }^{8}$ If the mid-expiratory flow rate (MMEF) was less than LLN; it was categorized as low MMEF.

\section{ANALYSIS}

Categorical variables were summarized in counts and percentages. The proportions were presented with $95 \%$ confidence intervals (Cl) and were compared by Pearson's chi-square test. The parametric variables were presented as mean \pm standard deviation, and the Student's t-test was used to compare the two groups. Logistic regression analysis was performed to assess the association between respiratory symptoms and abnormalities in FOT and spirometry. The odds ratios (OR) with $95 \% \mathrm{Cl}$ were used to assess the associations. The significance ( $\mathrm{p}$-value) was set at the 0.05 level. Statistical analysis was carried out by IBM ${ }^{\circledR}$ SPSS ${ }^{\circledR}$ Statistics Version 20.

\section{Results}

\section{Demographic characteristics}


We could establish direct contact with 1695 severely exposed subjects during the study period. Out of 1695 individuals, 916 (55.7\%) participated in this study. The reasons for the low participation are mentioned in figure 1 . The mean age of the study population was $55.2 \pm 12.3$ years. The majority ( $98.9 \%$ lived within a one-kilometer radius from the plant during exposure. $20.7 \%$ of individuals reported the death of at least one family member within one year. Two hundred twenty participants (24\%) mentioned admission to a hospital within one week after the disaster. More than one year of tobacco smoking was reported by $18.4 \%$ of individuals, and most were current smokers (77.4\%). Except for five women, all smokers were men. Smokers in the $\leq 55$-year age group were fewer than the older age group $(13.9 \%$ vs. $22.7 \%, \mathrm{p}<0.01)$.

The predominant comorbidity was systemic hypertension (37.0\%; 95\% Cl: 33.9- 40.2), followed by diabetes (14.4\%; $95 \%$ Cl: 12.3 - 16.8). Out of 916,558 participants $(60.9 \%)$ took part in lung function testing. The demographic characteristics, co-morbidities, and respiratory symptoms of those who took part in lung function testing $(n=558)$ and those who did not $(n=358)$ are compared in Table 1 . The demographic characteristics of both groups were comparable. Those who participated in lung function assessment had fewer coronary artery diseases than those who did not $(4.1 \%$ vs. $8.4 \% ; p<0.01)$.

\section{Respiratory morbidity}

The majority (79.6\%; 95\% Cl: 76.9 - 82.1) reported having at least one respiratory symptom. The predominant respiratory symptom was breathlessness on exertion (76.6\%; $95 \%$ Cl: 73.7-79.2), followed by cough (21.2\%; 95\% Cl: 18.7-23.9). The prevalence of chronic bronchitis based on the questionnaire was $15.5 \%$ (95\% Cl: 13.3-17.9). The individuals who participated in lung function assessment were less breathless $(71.7 \%$ vs. $88.5 \%$; $p<0.01)$, had less cough (15.1\% vs. $30.7 \%$; $p<0.01)$, and had less chronic bronchitis ( $9.9 \%$ vs. $24.3 \% ; p<0.01)$ compared to those who did not take part in lung function testing (Table 1 ).

The age group distribution between men and women in those who participated in the lung function assessment was similar (45.8\% of men vs. $45.6 \%$ of women had age $\leq 55$ years). Women had more breathlessness ( $78.4 \%$ vs. $64.7 \%$; $p<0.01)$, and less cough $(11.7 \%$ vs. $18.5 \% ; p=0.03)$ compared to men. Men had more chronic bronchitis than women (13.5\%. vs. $6.4 \% ; p<0.01)$. The individuals aged $\leq 55$ years had less breathlessness $(75.9 \%$ vs. $80.6 \%$; $p=0.05)$ and less cough $(18.1 \%$ vs. $24.2 \%, p=0.02)$ than individuals aged more than 55 years. However, chronic bronchitis in both age groups was not different ( $14.3 \%$ vs. $16.6 \% ; p=0.19)$.

\section{Forced oscillation technique}

Acceptable FOT was performed by 471 of 558 individuals (84.4\%) who participated in lung function assessments. The distribution of R5 and X5 of the study population is presented as the percentage predicted in figure 2 . The R5 and X5 $\geq 150 \%$ predicted was observed in $24.2 \%$ and $28.9 \%$ participants, respectively. The R5 >ULN was in $29.3 \%, R_{5-19}>$ LLN was in $23.3 \%$, and X5 <LLN was in $21.2 \%$ of participants (Table 3 ). We observe abnormal FOT in $37.7 \%$ of participants. The distribution of abnormal FOT was not different between men and women ( $36.1 \%$ in men vs. $39.3 \%$ in women, $P=0.27$ ).

\section{Spirometry}

Acceptable spirometry was performed by 452 participants ( $81 \%$ ). Normal, obstructive, and restrictive spirometry was observed in $46.2 \%, 26.1 \%$, and $27.7 \%$, respectively (Table 3). Obstructive spirometry in men was more compared to women (31.3\% vs. $20.3 \%$, p<0.05). The airflow obstruction was mainly mild $(45.8 \%)$. The women had more restrictive spirometry than men (33.5\% vs. $22.5 \%, p<0.05)$. Most of the restrictive spirometry was mild to moderate $(68.8 \%)$.

The lung function abnormalities are compared according to age groups (Table 4). The risk of abnormal X5, $R_{5-19}$, obstructive, and restrictive spirometry was significantly higher in individuals with age $>55$ years. The risk of abnormal $X 5$ and $R_{5-19}$ and restrictive spirometry in the older age group remained significant, despite adjusting for smoking.

Three hundred eighty-six participants (69.2\%) performed both acceptable FOT and spirometry. Table 5 illustrates the relationship between FOT parameters with spirometry outcomes of these individuals. The R5 > ULN, $R_{5-19}>U L N$, and X $5<L L N$ were observed in $17.7 \%, 15.1 \%$, and $8.1 \%$ of participants with normal spirometry. Individuals with obstructive spirometry had a higher risk of abnormal FOT parameters (adj OR: 3.93, 95\% Cl: 2.24-6.89). Both obstructive and restrictive spirometry had the highest risk of abnormal X5 among all FOT parameters.

\section{Relationship of respiratory symptoms with lung function parameters}

Table 6 illustrates the relationship of respiratory symptoms with abnormalities in FOT and spirometry parameters. Among FOT parameters, breathlessness had significant association with abnormal R5 (OR: 1.81; 95\% Cl: $1.13-2.91)$ and abnormal FOT (OR: 1.73; $95 \%$ Cl: 1.12 - 2.68). Among spirometry parameters, breathlessness showed a significant association with obstructive spirometry (OR: 2.26; 95\% Cl: 1.29-3.95) and low MMEF (OR: 2.35; 95\% Cl: 1.42-3.87). The adjusted odds for having cough with abnormalities in FOT parameters were statistically non-significant. Among spirometry parameters, cough showed a significant association with MMEF (OR: 3.04; $95 \%$ Cl: 1.74-5.34) only.

\section{Discussion}

In this study, we characterized the respiratory symptoms in survivors of the Bhopal gas disaster and assessed their lung functions by both FOT and spirometry. The majority complained of breathlessness. Abnormalities in spirometry were observed in nearly half of those who performed acceptable spirometry. The abnormalities in FOT, suggestive of SAD, were independent of abnormalities in spirometry.

After any toxic inhalational disaster, population-based studies are vital in understanding the pathophysiological mechanisms of lung injury, long-term sequel, and developing appropriate medical management. Besides the Bhopal gas disaster, many individuals were exposed to the dust of building materials during the World Trade Center (WTC) attack. The gases of the Bhopal gas disaster were lethal compared to the dust of the WTC attack. Extensive research and long- 
term follow-up of the exposed population in the WTC attack helped us understand lung injury pathogenesis following toxic inhalation. However, long-term follow-up lung function in the Bhopal gas disaster survivors is lacking.

Aftermath any disaster, over or under-reporting of symptoms in the exposed population is anticipated due to various medical and non-medical causes. Most of our study population mentioned having at least one respiratory symptom. The morbidity data of the ongoing long-term epidemiological study of the ICMR are collected either from the head of the family or any adult family member available during the surveys. In contrast, the morbidity data of the current study were collected through face-to-face interaction. This might be a possible reason for observing higher respiratory morbidity than previous reports of long-term epidemiological study. ${ }^{1-3}$

Lung function assessment is essential to evaluate the adverse effects of toxic inhalations. Immediately after the disaster and subsequently, several studies were conducted to estimate the lung function abnormalities in survivors of the Bhopal gas disaster. Spirometry was mostly used to assess lung functions. The type, severity, and distribution of abnormalities in spirometry were widely variable across those studies. ${ }^{11}$ We also observed new abnormalities in spirometry and rapid decline in spirometry parameters in survivors with respiratory symptoms. ${ }^{12}$ The last publication on lung function of the Bhopal gas disaster survivors was a retrospective analysis of spirometry reports of those who consulted a particular hospital for their respiratory problems. ${ }^{12}$ That study reported an obstructive pattern as the predominant abnormality (50.8\%), followed by a restrictive pattern (13.3\%). The current study being a community-based might be the reason for the different distribution of abnormalities in spirometry. Cullinan et al. were the first to report reduced MMEF, a subtle spirometry marker of SAD in the Bhopal Gas Disaster exposed population. ${ }^{13}$ They observed that those were living near the pesticide plant had significantly reduced MMEF. However, they had not reported the prevalence of MMEF abnormalities. Nearly one-third of our population had MMEF $<$ LLN.

The individuals exposed to the WTC attack had persistent respiratory morbidity and lung function abnormalities over decades. ${ }^{14,15}$ Therefore, lung function abnormalities in the exposed population of the Bhopal gas disaster, even over thirty years after the exposure, were not surprising. We observed that the lung function abnormalities were less in those exposed in their early life than older ones. This was possibly due to the wane of exposure effects as the children grown.

$\mathrm{FEV}_{1}$ predominantly reflects the obstruction of medium to large-sized airways. A significant amount of small airway resistance must be built up to make $\mathrm{FEV}_{1}$ abnormal. ${ }^{16}$ Spirometry fails to detect complex heterogeneous pathology of airways, especially if subtle abnormalities are present in the small airways. FOT and Impulse Oscillometry (IOS) are two noninvasive techniques used to assess small airway function. Both these techniques measure respiratory system resistance (Rrs) and reactance (Xrs), the two components of respiratory impedance. Rrs represent impedance to airflow, primarily reflecting overall airway caliber. Whereas, Xrs represents impedance to volume changes and encompasses both the respiratory system's inertial and elastic properties. The evaluation of small airway function in participants exposed to WTC attack provided valuable information that was rarely apparent in the spirometry. ${ }^{14,15}$ Oppenheimer et al. highlighted IOS as a better way of identifying SAD in subjects exposed to the WTC attack. ${ }^{17}$ The association of small airway dysfunctions in the exposed population of the WTC attack with persistent respiratory symptoms is well established. ${ }^{14,19}$ Breathlessness in our study population had a significant association with the abnormalities of both FOT and spirometry. Like the WTC attack exposed population, we also found abnormalities in IOS parameters independent of spirometry abnormalities. Sriramachari histopathologically documented the involvement of small airways in lung autopsies of the exposed population of the Bhopal gas disaster. ${ }^{18}$ He showed necrotizing bronchiolitis with denudation of the epithelium, in addition to severe tracheitis and bronchitis. Our study is the first to investigate and document SAD in survivors of the Bhopal gas disaster.

The restrictive spirometry of the WTC disaster was attributed to the involvement of small airways. ${ }^{20}$ SAD closes small airways at tidal volume, leading to restrictive spirometry. We also observed the presence of SAD in participants with restrictive spirometry. Few individuals with restrictive spirometry in our study also undergone radiological evaluations; however, no evidence of fibrosis or scarring was found in their chest X-rays.

The major limitations of this study were cross-sectional design, low participation, recruitment was restricted to only severely exposed cohort, no comparator group, and nearly half of the recruited individuals participated in lung function assessment. Therefore, the observation of this study may not be generalized to the survivors of the Bhopal gas disaster. The causes of low participation were busy with livelihood, lack of interest, no financial benefits for participation, change of residence, local migration, etc. We were also unable to establish contact with the individuals who are usually at work during our study visits, and they were probably healthier. There was a potential risk of selection bias, as those with relatively fewer respiratory symptoms participated in lung function assessments. This study was conducted over thirty years after the exposure, and some participants were also exposed to occupational and ambient air pollution in the succeeding years. In the absence of longitudinal lung function assessments, we cannot attribute the observed lung function abnormalities to exposure only. Post-bronchodilator spirometry and FOT were not performed due to logistics issues. Lung volume estimation of participants with restrictive spirometry was also not performed to confirm reduced total lung capacity. The strength of this study was that participants were part of the original cohort of the long-term epidemiological study. Therefore, their exposure to the disaster was undoubted.

In conclusion, this study highlighted self-reported respiratory morbidity and abnormalities in lung functions. Those who were exposed in early childhood had lesser lung function abnormalities compared to older ones. Lung function abnormalities are complex, and small airway dysfunction was independent of spirometry. A comprehensive lung function assessment by both spirometry and FOT is indispensable in assessing the effects of inhalational exposures.

\section{References}

1. Indian Council of Medical Research. Health effects of the toxic gas leak from the union carbide methyl isocyanate plant in Bhopal. Technical report on population based long term epidemiological studies (1985-1994). Available from http://www.nireh.org/assets/pdf/technical\%20reports/TR-Epid.pdf 
2. Indian Council of Medical Research. Health effects of the toxic gas leak from the Union Carbide Methyl Isocyanate plant in Bhopal. Population based long term epidemiological studies part II (1996-2010). Available from

http://www.nireh.org/assets/pdf/technical\%20reports/Technical\%20Report\%20on\%20Population\%20based\%20Long\%20term\%20epidemiological\%20Stu II.pdf

3. S De, D Shanmugasundaram, S Singh, N Banerjee, K K Soni, R Galgalekar. Chronic respiratory morbidity in the Bhopal gas disaster cohorts: a time-trend analysis of cross-sectional data (1986-2016). Public Health 2020; 186:20-27.

4. Jindal SK, Aggarwal AN, Gupta D, Agarwal R, Kumar R, Kaur, T et al. Indian study on epidemiology of asthma, respiratory symptoms and chronic bronchitis in adults (INSEARCH). Int J Tuberc Lung Dis. 2012;16:1270-7.

5. Oostveen E, MacLeod D, Lorino H, Farré R, Hantos Z, et al.; ERS Task Force on respiratory impedance measurements. The forced oscillation technique in clinical practice: methodology, recommendations and future developments. Eur Respir J. 2003;22:1026-41.

6. De S, Banerjee N, Kushwah GDS, Dharwey D. Regression equations of respiratory impedance of Indian adults measured by forced oscillation technique. Lung India. 2020;37:30-36.

7. Bednarek M, Grabicki M, Piorunek T, Batura-Gabryel H. Current place of impulse oscillometry in the assessment of pulmonary diseases. Respir Med. 2020;170:105952.

8. Miller MR, Hankinson J, Brusasco V, Burgos F, Casaburi R, et al.; ATS/ERS Task Force. Standardisation of spirometry. Eur Respir J. 2005;26:319-38.

9. Chhabra SK, Kumar R, Gupta U, Rahman M, Dash DJ. Prediction equations for spirometry in adults from northern India. Indian J Chest Dis Allied Sci. 2014;56:221-9.

10. Global initiative for chronic obstructive lung disease (GOLD). Global Strategy for Diagnosis, Management and Prevention of COPD.2020.https://goldcopd.org/wp-content/uploads/2019/11/GOLD-2020-REPORT-ver1.0wms.pdf

11. De S. Retrospective analysis of lung function abnormalities of Bhopal gas tragedy affected population. Indian J Med Res 2012;135:193-200.

12. De S. Annual change in spirometric parameters among patients affected in Bhopal gas disaster: A retrospective observational study. Lung India. 2013;30:103-7.

13. Cullinan P, Acquilla S, Dhara VR. Respiratory morbidity 10 years after the Union Carbide gas leak at Bhopal: a cross sectional survey BMJ 1997;314:338342.

14. Friedman SM, Maslow CB, Reibman J, Pillai PS, Goldring RM, et al. Case-control study of lung function in World Trade Center Health Registry area residents and workers. Am J Respir Crit Care Med. 2011;184:582-9.

15. Jordan HT, Friedman SM, Reibman J, Goldring RM, Miller Archie SA, et al. Risk factors for persistence of lower respiratory symptoms among community members exposed to the 2001 World Trade Center terrorist attacks. Occup Environ Med. 2017;74:449-455.

16. Petousi N, Talbot NP, Pavord I, Robbins PA. Measuring lung function in airways diseases: current and emerging techniques. Thorax. 2019;74:797-805.

17. Oppenheimer BW, Goldring RM, Herberg ME, Hofer IS, Reyfman PA, et al. Distal airway function in symptomatic participants with normal spirometry following World Trade Center dust exposure. Chest. 2007;132:1275-82.

18. Sriramachari S. The Bhopal gas tragedy: An environmental disaster. Curr Sci. 2004;86:905-20.

19. Caplan-Shaw C, Kazeros A, Pradhan D, Berger K, Goldring R, et al. Improvement in severe lower respiratory symptoms and small airway function in World Trade Center dust exposed community members. Am J Ind Med. 2016;59:777-87.

20. Berger KI, Reibman J, Oppenheimer BW, Vlahos I, Harrison D, et al. Lessons from the World Trade Center disaster: airway disease presenting as restrictive dysfunction. Chest. 2013;144:249-57.

\section{Tables}

\section{TABLE 1. Demographic characteristics and respiratory symptoms of the study population}




\begin{tabular}{|c|c|c|c|c|}
\hline Variables & $\begin{array}{l}\text { Participated in lung function } \\
\text { assessments }(\mathrm{n}=558)\end{array}$ & $\begin{array}{l}\text { Not participated in lung function } \\
\text { assessments }(n=358)\end{array}$ & $\begin{array}{c}\text { p- } \\
\text { value }\end{array}$ & Total $(\mathrm{N}=916)$ \\
\hline Age (yr), mean \pm SD & $55.8 \pm 11.6$ & $54.3 \pm 13.2$ & 0.08 & $55.2 \pm 12.3$ \\
\hline Men, n (\%) & $275(49.3)$ & $167(46.6)$ & 0.46 & $442(48.3)$ \\
\hline $\begin{array}{l}\text { Smoked for }>1 \text { yr, } n \\
\text { (\%) }\end{array}$ & $107(19.2)$ & $61(17.0)$ & 0.23 & \begin{tabular}{|l}
168 (18.4) \\
(95\% CI: $15.9-$ \\
$20.9)$ \\
\end{tabular} \\
\hline \multicolumn{5}{|l|}{ Comorbidities } \\
\hline $\begin{array}{l}\text { Diabetes mellitus, } \\
\text { n (\%) }\end{array}$ & $75(13.4)$ & $57(15.9)$ & 0.43 & $\begin{array}{c}132(14.4) \\
(95 \% \text { CI: } 12.3- \\
168)\end{array}$ \\
\hline Hypertension, $\mathbf{n}(\%)$ & $205(36.7)$ & $134(37.4)$ & 0.83 & $\begin{array}{c}339(37.0) \\
(95 \% \text { CI: } 33.9 \\
40.2) \\
\end{array}$ \\
\hline $\begin{array}{l}\text { Coronary artery } \\
\text { disease } \\
\text { n (\%) }\end{array}$ & $23(4.1)$ & $30(8.4)^{*}$ & 0.00 & $\begin{array}{l}53 \text { (5.8) } \\
\text { (95\% CI: } 4.5- \\
7.5) \\
\end{array}$ \\
\hline BMI $\left(\mathrm{kg} / \mathrm{m}^{2}\right)$ & $24.6 \pm 5.2$ & - & & - \\
\hline Breathlessness, $n$ (\%) & $400(71.7)$ & $317(88.5)^{*}$ & 0.00 & $\begin{array}{c}717 \text { (78.3) } \\
(95 \% \text { CI: } 75.5- \\
80.8) \\
\end{array}$ \\
\hline Cough, n (\%) & $84(15.1)$ & $110(30.7)^{*}$ & 0.00 & $\begin{array}{c}194(21.2) \\
(95 \% \text { CI: } 18.7- \\
23.9) \\
\end{array}$ \\
\hline $\begin{array}{l}\text { Chronic bronchitis, } \mathrm{n} \\
\text { (\%) }\end{array}$ & $55(9.9)$ & $87(24.3)^{*}$ & 0.00 & $\begin{array}{c}\text { 142 (15.5) } \\
\text { (95\% CI: 13.3- } \\
17.9)\end{array}$ \\
\hline
\end{tabular}

BMI: body mass index; *p-value $<0.01$; CI: confidence interval

Table 2. The distribution of abnormality in Forced Oscillation Technique according to gender

\begin{tabular}{l|c|c|c|c|}
\hline ariables & $\begin{array}{c}\text { Men (=242) } \\
\mathbf{n}(\%)\end{array}$ & $\begin{array}{c}\text { Femen (=229) } \\
\mathbf{n}(\%)\end{array}$ & p-value & $\begin{array}{c}\text { Total (=471), } \\
\mathbf{n}(\%),(95 \% \text { CI })\end{array}$ \\
\hline $5>$ ULN & $65(26.9)$ & $73(31.9)$ & 0.14 & $\begin{array}{c}138(29.3) \\
(25.4-35.6)\end{array}$ \\
\hline $5<$ LLN & $47(19.4)$ & $53(23.1)$ & 0.19 & $\begin{array}{c}100(21.2) \\
(17.8-25.2)\end{array}$ \\
\hline $5-19>$ ULN & $54(22.4)$ & $55(24.3)$ & 0.66 & $\begin{array}{c}109(23.3) \\
(19.6-27.2)\end{array}$ \\
\hline bnormal FOT & $87(36.1)$ & $90(39.3)$ & 0.50 & $\begin{array}{c}177(37.7) \\
(33.3-42.0)\end{array}$ \\
\hline
\end{tabular}

R5: Whole-breath resistance at $5 \mathrm{~Hz}$; X5: Whole-breath reactance at $5 \mathrm{~Hz}$; $\mathrm{R}_{5-19}$ : Frequency-dependence resistance; ULN: upper limit of normal; LNN: lower limit of normal.

Table 3. The distribution of spirometry abnormality and severity of abnormality according to gender

\begin{tabular}{|c|c|c|c|}
\hline Variables & $\begin{array}{c}\text { Men }(=240), \\
n(\%)\end{array}$ & $\begin{array}{c}\text { Women }(=212), \\
n(\%)\end{array}$ & $\begin{array}{c}\text { Total }(=452), \\
n(\%)\end{array}$ \\
\hline Normal spirometry & $111(46.3)$ & $98(46.2)$ & $\begin{array}{c}209(46.2) \\
\text { (95\% CI: 41.7-50.9) }\end{array}$ \\
\hline Obstructive pattern & $75(31.3)$ & $43(20.3)^{*}$ & $\begin{array}{c}118(26.1) \\
\text { (95\% CI: } 22.3-30.4)\end{array}$ \\
\hline Mild airflow obstruction & $36(48)$ & $18(41.9)^{*}$ & $54(45.8)$ \\
\hline Moderate airflow obstruction & $13(17.3)$ & $8(18.6)$ & $21(17.8)$ \\
\hline $\begin{array}{l}\text { Moderately severe airflow } \\
\text { obstruction }\end{array}$ & $12(16.0)$ & $11(25.6)$ & $23(19.5)$ \\
\hline Severe airflow obstruction & $12(16.0)$ & $6(14.0)$ & $18(15.3)$ \\
\hline Very severe airflow obstruction & $2(2.7)$ & 0 & $2(1.7)$ \\
\hline Restrictive pattern & $54(22.5)$ & $71(33.5)^{*}$ & $\begin{array}{c}125(27.7) \\
\text { (95\% CI: } 23.7-31.9) \\
\end{array}$ \\
\hline Mild restriction & $15(27.8)$ & $27(38.0)$ & $42(33.6)$ \\
\hline Moderate restriction & $22(40.7)$ & $22(31.0)$ & $44(35.2)$ \\
\hline Moderately severe restriction & $9(16.7)$ & $16(22.5)$ & $25(20.0)$ \\
\hline Severe restriction & $8(14.8)$ & $4(5.6)$ & $12(9.6)$ \\
\hline Very severe restriction & 0 & $2(2.8)$ & $2(1.6)$ \\
\hline MMEF $<L_{L N}^{\#}$ & $99(41.4)$ & $44(30.8)^{*}$ & $\begin{array}{c}143(30.6) \\
\text { (95\% CI: 26.6-34.9) }\end{array}$ \\
\hline
\end{tabular}

${ }^{*} \mathrm{p}<0.05$; CI: confidence interval, MMEF: mid expiratory flow rate; LLN: lower limit of normal; \# : MMEF data were available for 468 subjects 
Table 4. The age group-wise distribution of lung function abnormality

\begin{tabular}{|l|c|c|c|c|}
\hline \multicolumn{1}{|c|}{ Variables } & \multicolumn{2}{c|}{ Age group } & \multicolumn{2}{c|}{ Odds ratio, (95\% CI) } \\
\hline & <55 years (=213) $\mathbf{n ~ ( \% ) ~}$ & $\begin{array}{c}\mathbf{\geq} \text { 55 years (=258) } \\
\mathbf{n}(\%)\end{array}$ & Un-adjusted & Adjusted* \\
\hline R5>ULN & $58(27.2)$ & $80(31.0)$ & $1.20(0.80-1.79)$ & $1.17(0.78-1.53)$ \\
\hline X5<LLN & $29(13.6)$ & $71(27.5)$ & $2.41(1.49-3.88)^{\#}$ & $2.26(1.39-3.66)^{\#}$ \\
\hline$R_{5-19}>$ ULN & $37(17.6)$ & $72(28.0)$ & $1.82(1.16-2.85)^{\#}$ & $1.66(1.05-2.62)^{\wedge}$ \\
\hline & & & & \\
\hline Obstructive pattern & $46(20.6)$ & $72(31.6)$ & $1.78(1.16-2.74)^{\#}$ & $1.49(0.95-2.33)$ \\
\hline Restrictive pattern & $50(22.3)$ & $75(32.9)$ & $1.71(1.12-2.59)^{\wedge}$ & $1.89(1.23-2.89)^{\#}$ \\
\hline MMEF <LLN@ & $72(50.3)$ & $71(49.7)$ & $0.91(0.61-1.35)$ & $0.74(0.49-1.12)$ \\
\hline
\end{tabular}

* Adjusted for smoking; R5: Whole-breath resistance at $5 \mathrm{~Hz}$; X5: Whole-breath reactance at 5 Hz; $\mathrm{R}_{5-19}$ : Frequency-dependent resistance; ULN: upper limit of normal; LNN: lower limit of normal; MMEF: Maximum mid-expiratory flow rate; @ acceptable MMEF was obtained from 468 cases; ${ }^{*} \mathrm{p}<0.01 ; \wedge$ p $<0.05$.

Table 5. The distribution of FOT abnormality with spirometry results

\begin{tabular}{|l|c|c|c|}
\hline Variables & Normal spirometry (=186) $\mathbf{n ~ ( \% ) ~}$ & Obstructive pattern (=92) n (\%) & Restrictive pattern (=108) n (\%) \\
\hline R5 > ULN & $33(17.7)$ & $47(51.1)$ & $33(30.6)$ \\
\hline Adjusted Odds ratio* (95\% CI) & 1 & $4.88(2.71-8.77)$ & $2.02(1.15-3.54)$ \\
\hline X5 < LLN & $15(8.1)$ & $38(41.3)$ & $31(28.7)$ \\
\hline Adjusted Odds ratio* (95\% CI) & 1 & $6.66(3.31-13.42)$ & $4.07(2.06-8.07)$ \\
\hline & $28(15.1)$ & $36(40.4)$ & $28(25.9)$ \\
\hline $\mathbf{R}_{5-19}>$ ULN & 1 & $3.09(1.67-5.73)$ & $1.82(0.99-3.31)$ \\
\hline Adjusted Odds ratio* (95\% CI) & $47(25.3)$ & & $43(39.8)$ \\
\hline Abnormal FOT & 1 & $3.93(2.24-6.89)$ & $1.90(1.14-3.18)$ \\
\hline Adjusted Odds ratio* (95\% CI) & & & \\
\hline
\end{tabular}

*Adjusted for age (continuous variable) and smoking status (binary variable); R5: Whole-breath resistance at 5 Hz; X5: Whole-breath reactance at $5 \mathrm{~Hz} ; \mathrm{R}_{5-19}$ : Frequency-dependence of resistance; ULN: upper limit of normal; LNN: lower limit of normal.

Table 6. The association of respiratory symptoms with an abnormality in FOT and spirometry parameters

\begin{tabular}{|c|c|c|c|c|c|c|c|c|}
\hline \multirow[t]{3}{*}{ Variables } & \multicolumn{4}{|c|}{ Breathlessness } & \multicolumn{4}{|c|}{ Cough } \\
\hline & \multirow{2}{*}{$\begin{array}{c}\text { Breathless n } \\
(\%)\end{array}$} & \multirow{2}{*}{$\begin{array}{c}\text { Not } \\
\text { breathless } \\
\text { n (\%) }\end{array}$} & \multicolumn{2}{|c|}{ Odds ratio, (95\% CI) } & \multirow{2}{*}{$\begin{array}{l}\text { Cough } \\
\text { n (\%) }\end{array}$} & \multirow{2}{*}{$\begin{array}{l}\text { No } \\
\text { cough } \\
\text { n (\%) }\end{array}$} & \multicolumn{2}{|c|}{ Odds ratio, $(95 \% \mathrm{CI})$} \\
\hline & & & $\begin{array}{c}\text { Un- } \\
\text { adiusted }\end{array}$ & Adjusted* & & & $\begin{array}{c}\text { Un- } \\
\text { adiusted }\end{array}$ & Adjusted* \\
\hline Abnormal R5 (R5 > ULN) & $\begin{array}{c}109 \\
(32.9)\end{array}$ & $\begin{array}{c}29 \\
(20.7)\end{array}$ & $\begin{array}{c}1.88 \\
(1.18-3.0)\end{array}$ & $\begin{array}{l}1.81 \\
(1.13- \\
2.91)\end{array}$ & $\begin{array}{c}24 \\
(34.3)\end{array}$ & $\begin{array}{c}114 \\
(28.4)\end{array}$ & $\begin{array}{l}1.31 \\
(0.77- \\
2.25)\end{array}$ & $\begin{array}{c}1.24 \\
(0.72 \\
-2.15)\end{array}$ \\
\hline AbnormalX5 (X5< LLN) & $\begin{array}{c}80 \\
(24.2)\end{array}$ & $\begin{array}{c}20 \\
(14.3)\end{array}$ & $\begin{array}{l}1.91 \\
(1.12- \\
3.27)\end{array}$ & $\begin{array}{l}1.60 \\
(0.92- \\
2.78)\end{array}$ & $\begin{array}{c}18 \\
(25.7)\end{array}$ & $\begin{array}{c}82 \\
(20.4)\end{array}$ & $\begin{array}{l}1.35 \\
(0.75- \\
2.43)\end{array}$ & $\begin{array}{l}1.08 \\
(0.58- \\
2.0)\end{array}$ \\
\hline $\begin{array}{l}\text { Abnormal } R_{5-19} \\
\left(R_{5-19}>\text { ULN }\right)\end{array}$ & $\begin{array}{c}84 \\
(25.7)\end{array}$ & $\begin{array}{c}25 \\
(17.9)\end{array}$ & $\begin{array}{l}1.59 \\
(0.96- \\
2.62)\end{array}$ & $\begin{array}{l}1.34 \\
(0.81 \\
-2.24)\end{array}$ & $\begin{array}{c}18 \\
(26.1)\end{array}$ & $\begin{array}{c}91 \\
(22.9)\end{array}$ & $\begin{array}{l}1.19 \\
(0.66- \\
2.14)\end{array}$ & $\begin{array}{l}0.95 \\
(0.51- \\
1.75)\end{array}$ \\
\hline Abnormal FOT & $\begin{array}{c}138 \\
(41.8)\end{array}$ & $\begin{array}{c}39 \\
(27.9)\end{array}$ & $\begin{array}{c}1.86 \\
(1.21- \\
2.86) \\
\end{array}$ & $\begin{array}{l}1.73 \\
(1.12- \\
2.68)\end{array}$ & $\begin{array}{c}29 \\
(41.4)\end{array}$ & $\begin{array}{c}148 \\
(37.0)\end{array}$ & $\begin{array}{c}1.20 \\
(0.72- \\
2.02) \\
\end{array}$ & $\begin{array}{c}1.01 \\
(0.99- \\
1.03) \\
\end{array}$ \\
\hline $\begin{array}{l}\text { Obstructive } \\
\text { pattern }\end{array}$ & $\begin{array}{c}99 \\
(30.7)\end{array}$ & $\begin{array}{c}19 \\
(14.7)\end{array}$ & $\begin{array}{l}2.56 \\
(1.49- \\
4.39)\end{array}$ & $\begin{array}{l}2.26 \\
(1.29- \\
3.95)\end{array}$ & $\begin{array}{c}29 \\
(43.9)\end{array}$ & $\begin{array}{c}89 \\
(23.1)\end{array}$ & $\begin{array}{l}2.62 \\
(1.52- \\
4.49)\end{array}$ & $\begin{array}{l}1.02 \\
(0.99- \\
1.04)\end{array}$ \\
\hline Restrictive pattern & $\begin{array}{c}97 \\
(30.0)\end{array}$ & $\begin{array}{c}28 \\
(21.7)\end{array}$ & $\begin{array}{l}1.55 \\
(0.95- \\
2.51)\end{array}$ & $\begin{array}{l}1.55 \\
(0.95 \\
-2.53)\end{array}$ & $\begin{array}{c}21 \\
(31.8)\end{array}$ & $\begin{array}{c}194 \\
(26.9)\end{array}$ & $\begin{array}{l}1.27 \\
(0.72- \\
2.23)\end{array}$ & $\begin{array}{l}1.36 \\
(0.76- \\
2.43)\end{array}$ \\
\hline MMEF<LLN & $\begin{array}{c}116 \\
(35.0)\end{array}$ & $\begin{array}{c}27 \\
(19.7)\end{array}$ & $\begin{array}{c}2.19 \\
(1.36 \\
-3.54)\end{array}$ & $\begin{array}{l}2.35 \\
(1.42- \\
3.87)\end{array}$ & $\begin{array}{c}35 \\
(53.8)\end{array}$ & $\begin{array}{c}108 \\
(26.8)\end{array}$ & $\begin{array}{l}2.20) \\
3.19 \\
(1.87- \\
5.44)\end{array}$ & $\begin{array}{l}2.104 \\
3.04 \\
(1.74- \\
5.34)\end{array}$ \\
\hline
\end{tabular}


*Adjusted by smoking status (binary variable) and age (continuous variable). R5: Whole-breath resistance at $5 \mathrm{~Hz}$; X5: Whole-breath reactance at $5 \mathrm{~Hz}$; $\mathrm{R}_{5-19}$ : Frequency-dependence of resistance; ULN: upper limit of normal; LNN: lower limit of normal.

\section{Declarations}

\section{Funding}

This project was supported by an Intramural Research Grant from the Indian Council of Medical Research, New Delhi. There was no role of the funding agency in the design, data collection, analysis, interpretation of data, and manuscript writing.

\section{Grant/award number}

Not applicable

\section{Conflict of Interest}

The authors declare that they have no known competing financial interests or personal relationships that could have appeared to influence the work reported in this paper.

\section{Running Title:}

Respiratory Morbidities and Lung Function abnormalities after the Bhopal Gas Disaster

\section{Contribution ship}

SD: Conceived the study, interpretation of data, and manuscript writing. NB: Data collection. YS: data interpretation. All authors read and approved the final manuscript.

\section{Acknowledgment}

The authors are grateful to Mr. G D S Khushwah, Mr. D Dharway, Mr. M Q Khan, and Mr. Sushil Silpi for their help in data collection.

\section{Ethics Approval Statement}

The Institutional Ethics Committee of the National Institute for Research in Environmental Health approved the study protocol (NIREH/BPL/1EC-prj.19/201718/1458)

\section{Competing interests}

All authors declare non-competing interests

Data Sharing/Data availability:Data can be shared for review only

\section{Figures}

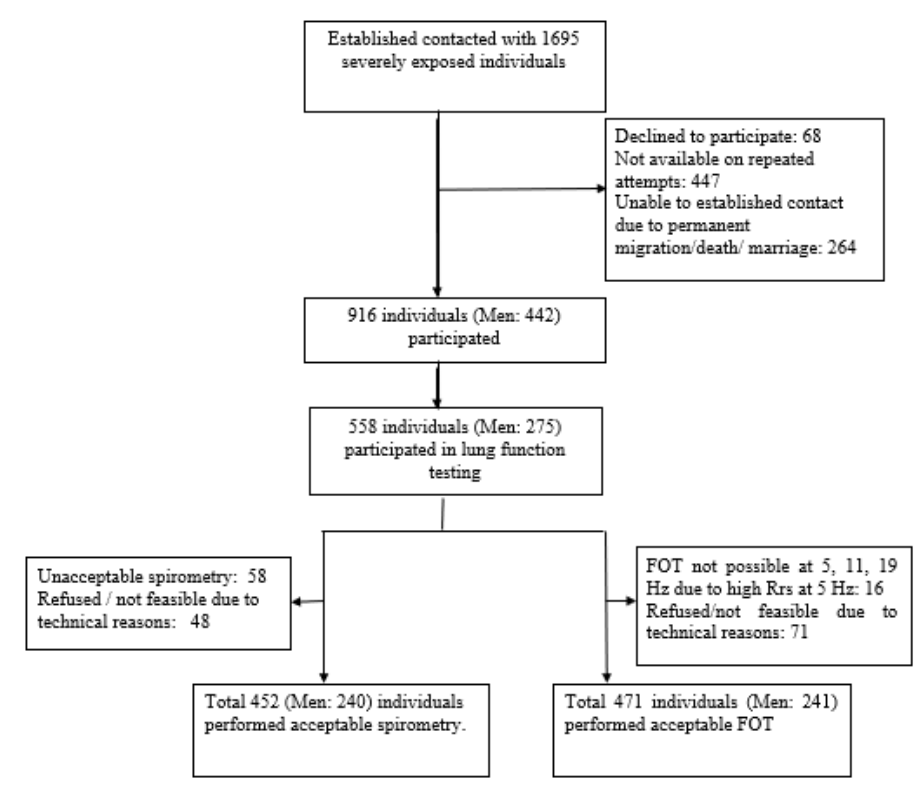

Figure 1 
Flow chart of subject recruitment.

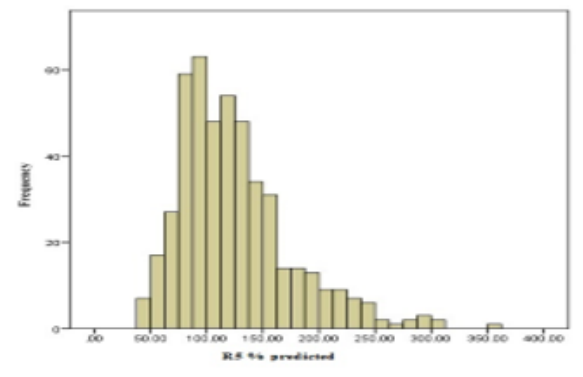

(A)

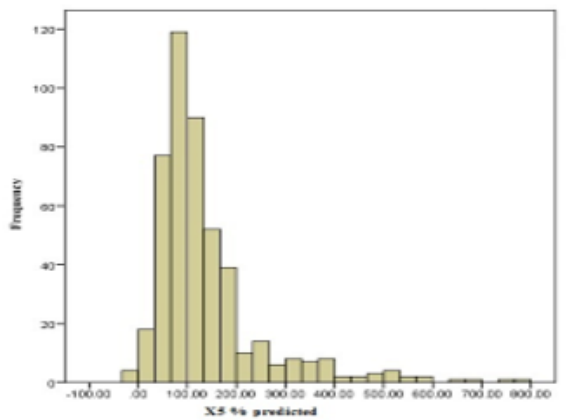

(B)

\section{Figure 2}

(A) Whole breath respiratory resistance at $5 \mathrm{~Hz}(\mathrm{R} 5)$ presented as percentage of predicted. (B) Whole breath respiratory reactance at $5 \mathrm{~Hz}(\mathrm{X} 5)$ presented as a percentage of predicted. 